\title{
Home intravenous antibiotic treatment in cystic fibrosis
}

\author{
J GILBERT, T ROBINSON, AND J M LITTLEWOOD
}

\author{
Regional Cystic Fibrosis Unit, St James's University Hospital, Leeds
}

\begin{abstract}
SUMmary The prognosis for patients with cystic fibrosis who are colonised with Pseudomonas aeruginosa has improved as a result of the regular use of intravenous antibiotics; however, this necessitates long periods of hospitalisation. Home intravenous antibiotic treatment has potential advantages over hospital treatment. We describe our experience during the first 20 months of using a system of home intravenous antibiotic treatment in which a cystic fibrosis liaison sister has an essential role. Thirteen patients have received 40 courses of treatment. There were highly significant improvements in weight, respiratory function, and white cell count during home treatment. There was no significant difference in weight and forced expiratory volume in one second between the end of home treatment and the end of hospital treatment while forced vital capacity was better after home treatment. All patients preferred home treatment. The advantages of home visits by the cystic fibrosis liaison sister during treatment are emphasised.
\end{abstract}

The prognosis for patients with cystic fibrosis who are colonised or infected with Pseudomonas aeruginosa has improved over recent years as a result of the regular use of intravenous antibiotics ${ }^{1}$ but this has necessitated long periods of hospitalisation for some patients. Inpatient treatment is disruptive and stressful even when mothers are resident. ${ }^{2}$ There are also financial strains, particularly when the patient is under the care of a specialist regional unit, which may be some distance from the patient's home. ${ }^{3}$ The need for regular intravenous treatment often starts during the second decade of life when time spent away from school or work may have a particularly deleterious effect on the individual's prospects for future employment. After several admissions most patients and parents became familiar with many aspects of intravenous drug administration and see no reason why they should not do it themselves.

Patients with cystic fibrosis requiring intravenous treatment are often not acutely ill but place a great strain on the accommodation, manpower, and financial resources of the hospital. Drugs may be given late by tired senior house officers who have never had any formal training in the administration of intravenous drugs. There is increasing concern about the possible dangers of cross infection of resistant strains of pseudomonas in hospitals, ${ }^{4}$ and there is increasing evidence that viral infections (which are usually rife in paediatric wards) can lead to pulmonary deterioration in patients with cystic fibrosis. $^{5}$

Treatment with intravenous antibiotics at home has been seen by both the patients and the medical profession as a way of avoiding some of the problems outlined above ${ }^{6}$; however, there are several potential problems with home treatment. ${ }^{6}$ Intensive physiotherapy and dietetic help are important adjuncts to antibiotic treatment and these will be limited when the patient is at home. Monitoring of the patients' progress with a view to altering treatment is also limited. Some patients require such frequent resiting of their cannulas that it would be pointless to attempt home treatment. It is evident that patients or parents must be capable of learning to give intravenous drugs safely. Patients with cystic fibrosis are routinely expected to take responsibility for much of their management and they may find further responsibilities more stressful than being admitted to hospital. The end results of treatment at home should not be inferior to inpatient treatment.

In February 1986 we introduced a system of home intravenous antibiotic treatment for patients under the care of the Leeds Regional Cystic Fibrosis Unit based at St James's University Hospital in which an essential role is played by a specially trained cystic fibrosis liaison sister. We present our experience and results with this system after 20 months. 


\section{Methods}

\section{PATIENT SELECTION}

The following criteria were considered before training for home intravenous treatment was offered:

(1) The patient should have had at least one course of intravenous treatment in hospital. This admission may be used to train the patient and family and assess ease of venous access.

(2) The patient and family should be considered to be compliant with other forms of treatment.

(3) Intravenous access should be reliable enough to ensure several days of treatment without the need for revision.

(4) The home must have been visited by the cystic fibrosis liaison sister to establish that there are suitable areas for safe storage of equipment and a clean area to prepare drugs.

(5) The family practitioner should have no objection to home treatment starting.

(6) The ability of the family to cope with current levels of stress and responsibility is informally assessed and previous home visits by the liaison sister or social worker are particularly helpful in relation to this.

(7) The family should have a telephone in the home.

INTRAVENOUS ACCESS

Intravenous access must be reliable. We used one of the following methods:

(1) Intermittent injection. Some patients have prominent and easily punctured antecubital veins and preferred to insert a 23 gauge butterfly needle (Venisystems) each time drugs were given. This method allowed great freedom of activity between drug administration.

(2) Cannula. An ordinary paediatric intravenous cannula was inserted in the forearm where movement was least likely to occur. A $20 \mathrm{~cm}$ extension allowed the patient to hold the injection bung easily in one hand while injecting with the other. A lock containing 10 units of heparin $/ \mathrm{ml}$ (Hepsal, CP Pharmaceuticals) maintained patency between drug administration. Cannules that failed could be replaced at the patient's home by the liaison sister.

(3) Neonatal long line. A $30 \mathrm{~cm}$ fine Silastic neonatal central venous line (Epicutaneo catheter, Vygon) was inserted into a antecubital vein and patency maintained by a lock containing 100 units of heparin $/ \mathrm{ml}$ (Hep-Flush, Edwin Burgess) as described by Tyrell et al. (J Tyrell, S Wynn, J Hiller. Experience with neonatal 'long lines' for antibiotic therapy in cystic fibrosis. Abstract to be published in Scandinavian Journal of Gastroenterology.) This system usually gave prolonged venous access and had the advantage over other long lines of being inserted through a small (19 gauge) needle and allowing great mobility.

(4) Totally implantable intravenous access devices (Port-A-Cath, Pharmacia). In patients with poor venous access who were going to need repeated courses of intravenous treatment this system allowed guaranteed access with a single skin puncture. ${ }^{7}$ The $90^{\circ}$ Huber point needle and short extension were changed every seven days.

\section{TRAINING}

The liaison sister trained parents and patients who were mature enough to learn to check, reconstitute, and dilute drugs as well as draw up and give them by slow bolus injection. Depending on the type of intravenous access being used instructions were also given on flushing the line, inserting a heparin lock, using butterfly needles, and managing a Port-ACath. A syringe pump was used for drugs that had to be infused over a long period. Care was taken to ensure that patients were aware of the signs of local problems with intravenous access and systemic drug reactions.

Patients and parents usually quickly acquired considerable skill and knowledge in all aspects of intravenous drug administration during inpatient treatment. Final instruction was given during the administration of the first dose of the first course of home intravenous treatment. The patient or parent gave the second dose of drugs under close observation. A member of staff confirmed on the home record of intravenous treatment that the patient/ parent was competent in both theory and practice; if they were found to be incompetent intravenous treatment at home had to be delayed. Written instructions were given to each family.

\section{STARTING TREATMENT}

All first doses were given in hospital and the patient was observed for 30 minutes after this and asked to stay in the hospital for a further 90 minutes. If a drug was used that the patient has not had before then the second dose was also given in hospital and observation continued for 30 minutes after this.

The time spent in hospital was used to examine the patient and check baseline weight and to 
perform respiratory function tests and haematological investigations.

The patient left the hospital with all the equipment and drugs for the first week of treatment (the family practitioner prescribed drugs for subsequent weeks' treatment), a container for 'sharps,' a peak expiratory flow meter, and record chart. They also had the home telephone numbers of the liaison sister and a member of the medical staff of the unit.

\section{MONITORING}

Blood for monitoring of aminoglycoside concentrations was collected by the liaison sister on the second or third day of treatment.

The patient kept a twice daily record of his peak expiratory flow and the liaison sister visited at least once a week (more often during the first course of treatment) to review progress by assessing the patient's general condition, degree of cough, and sputum volume and colour. Respiratory function could also be checked by a portable spirometer (Vitalograph-Compact, Vitalograph). Failure to improve led to a review of treatment. If compliance seemed poor or the family seemed to be having difficulty coping action was taken to correct this or terminate the home treatment.

\section{Results}

Forty courses totalling 596 days of home intravenous antibiotic treatment were given to 13 patients (eight girls, five boys) aged 9 to 28 years. Patients lived up to 80 miles from the hospital. At the start of the first course of home treatment Shwachman scores ranged from 50 to 90 (mean 72) and Chrispin Norman $x$ ray scores from 6 to 26 (mean 12). One patient received eight courses of treatment.

$P$ aeruginosa was the main pathogen at the start of 38 courses. In one course Haemophilus influenzae and in another course Staphylococcus aureus and $H$ influenzae were isolated at the start of treatment but in both instances $P$ aeruginosa had been isolated from the previous culture. The following antibiotics were used (number of courses of treatment): tobramycin (25), ceftazidime (22), azlocillin (12), amikacin (9), aztreonam (4), ticarcillin (4), and piperacillin (1). Venous access was by cannula in 15 courses, Port-A-Cath in 12, intermittant injection in 11 , and neonatal long line in six. Cannulas lasted between two and 13 days (mean four days) and neonatal long lines between four and 17 days (mean nine days).

Courses of home treatment lasted from seven to 36 days (mean 15) and in 15 courses there was some associated inpatient treatment lasting from two to 18 days (mean six days). Reasons for associated in-

patient treatment are shown in the table. Drug reactions were encountered in five courses. In two cases patients complained of generalised aches and tiredness that resolved within 24 hours of stopping azlocillin. Two patients had a mild rash and were admitted for change of treatment while one patient developed an urticarial rash within minutes of receiving intravenous tobramycin and ceftazidime at home. This patient was admitted, and subsequent challenge with ceftazidime precipitated an anaphylactoid reaction requiring intravenous chlorpheniramine and hydrocortisone.

There were highly significant improvements in weight $(n=34, p<0.0003)$, peak expiratory flow $(\mathrm{n}=38, \mathrm{p}<0.0001)$, forced expiratory volume in one second $(n=34, p<0.0001)$, forced vital capacity $(\mathrm{n}=34, \mathrm{p}<0 \cdot 0001)$, and white cell count $(\mathrm{n}=20$, $\mathrm{p}=0.009$ ) during home intravenous treatment (fig 1). There was symptomatic improvement during all courses of treatment except for the four indicated in fig 1 by symbols: in course 1 the patient had very advanced disease and died within two months of treatment. In course 2 the patient was admitted because of failure to improve adequately and did not start to improve until a week later. In course 3 the patient showed a deterioration in respiratory function that was not in keeping with his otherwise very good response to treatment. In course 4 there was clinical improvement but chest radiography showed signs of allergic bronchopulmonary aspergillosis and there was a rise in IgE. Steroid treatment produced a further improvement of respiratory function and clearing of the radiograph.

Weight, forced expiratory volume in one second, and forced vital capacity were compared at the end of the most recent course of hospital treatment with the end of the course of home intravenous treatment closest to it (fig 2). All three of these parameters

Table Inpatient treatment associated with home intravenous treatment $(n=15)$

\begin{tabular}{lll}
\hline & $\begin{array}{l}\text { No of } \\
\text { courses }\end{array}$ & Reason \\
\hline $\begin{array}{c}\text { Inpatient treatment } \\
\text { before outpatient } \\
\text { treatment }\end{array}$ & 6 & $\begin{array}{l}\text { For initial stabilisation } \\
\text { Previous drug reaction } \\
\text { Post partum (24 year old) } \\
\text { Insertion of Port-A-Cath }\end{array}$ \\
$\begin{array}{l}\text { Inpatient treatment } \\
\text { between outpatient } \\
\text { treatment }\end{array}$ & 1 & Chest pains \\
$\begin{array}{l}\text { Inpatient treatment } \\
\text { after outpatient } \\
\text { treatment }\end{array}$ & 1 & \\
\hline
\end{tabular}




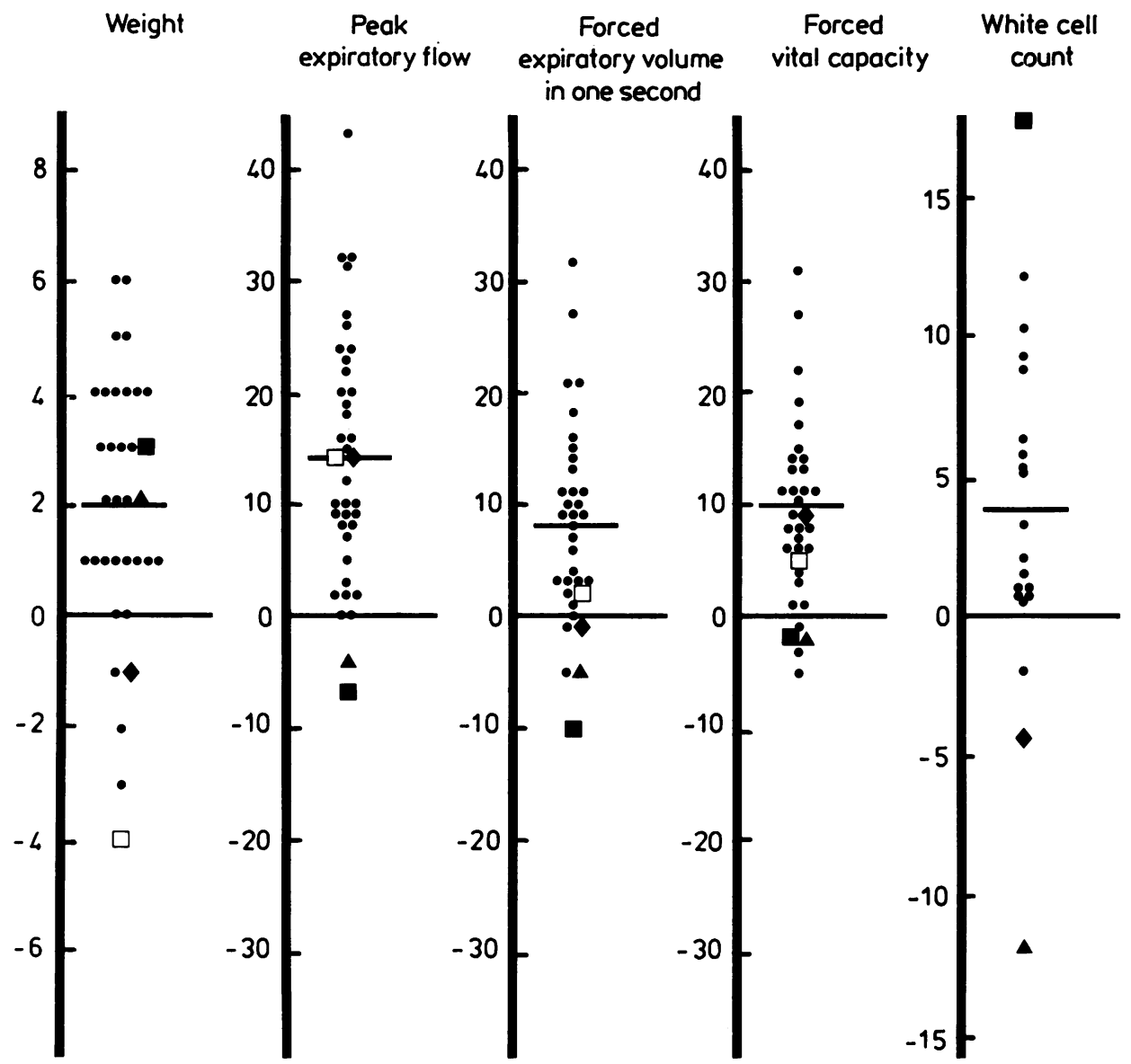

Fig 1 Changes during home intravenous treatment. Weight is expressed as change in percentage predicted weight for height. Peak expiratory flow, forced expiratory volume in one second, and forced vital capacity are expressed as changes in percentage predicted. White cell count is expressed as the fall in the number of white cells $\times 10^{9} / 1-$ that is, a negative result indicates a rise in white cell count. Course $1(\Delta)$; course $2(\square)$; course $3(\square)$; course $4(\diamond)$.

were better after home treatment than after hospital treatment and this reached significance for forced vital capacity (weight $(n=11)$, not significant; forced expiratory volume in one second $(n=10)$, not significant; and forced vital capacity $(n=10)$, $\mathrm{p}=0 \cdot 025)$.

One patient had not had any previous inpatient treatment but he and his mother were exceedingly distressed by the prospect of admission because his sister had died of leukaemia on the paediatric ward at this hospital a few years earlier.

One patient was refused further use of the service after the discovery of a 1 year old child playing with vials of heparin when the liaison sister visited.

Another patient (results not included) received prolonged intravenous treatment at home during the terminal phase of her disease and both she and her parents found this preferable to hospital admission or withdrawal of antipseudomonal antibiotics. The sibling of this patient subsequently needed intravenous treatment and the parents felt able to cope with this at home, however, an early visit by the liaison sister showed a high level of stress and the remainder of the treatment was given in hospital.

No one has yet rejected the idea of home treatment when it has been offered. One family have been unable to start home treatment because of unsuitable housing conditions. Several families have asked about home intravenous treatment but have been temporarily refused because of poor venous access.

The reaction of families to home and hospital 


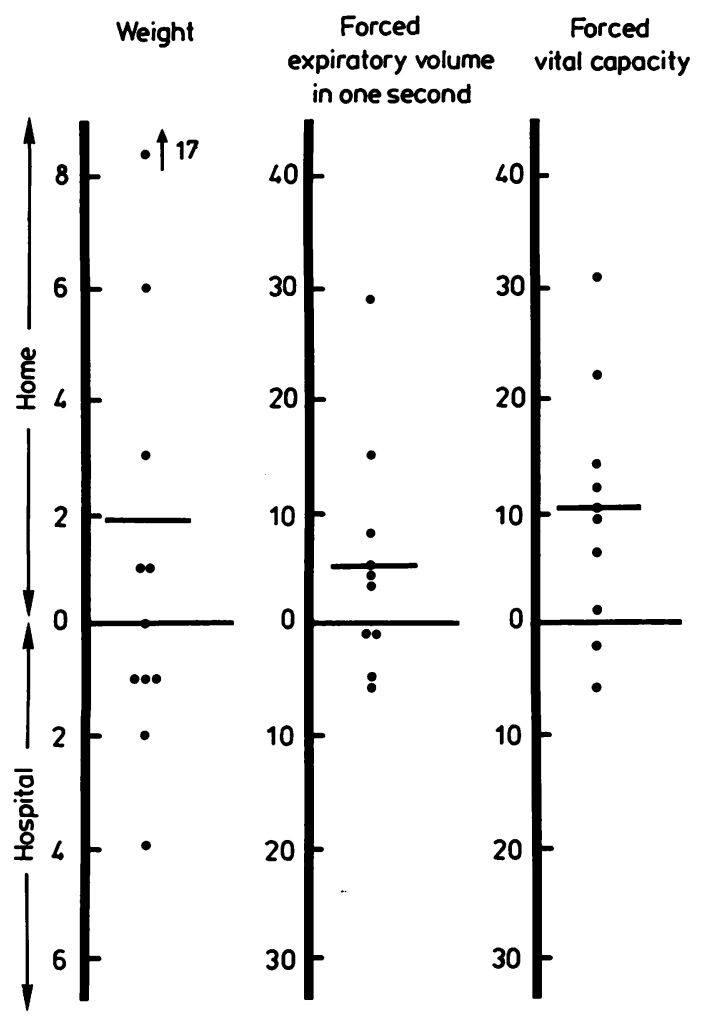

Fig 2 Comparison of weight and respiratory function after home and hospital intravenous treatment. Weight for height and percentage of predicted forced expiratory volume in one second and forced vital capacity expressed as difference after hospital and home treatment-that is, those below the zero line were better after hospital treatment.

treatment were canvassed using a postal questionnaire which included a visual analogue scale to assess the stress of inpatient and outpatient treatment. All families preferred home treatment. Reasons for preferring home treatment included better food, more facilities to exercise, better sleep patterns, better timing of drug administration, and less interruption of education and career. The advantages of hospital treatment were considered to be more effective physiotherapy and the reassurance of having medical help at hand. During home treatment eight patients attended work or school for more than $50 \%$ of the time and most families found financial advantages (of up to $£ 110$ per week) because of reduced travelling expenses to hospital and because earnings were not lost. All families felt some degree of stress during home treatment but only two considered this greater than the stress of a hospital admission (and even these patients preferred to continue with home treatment).
On the basis of the cost of inpatient accommodation alone ( $£ 81.37$ per day) the home intravenous service is saving $£ 29098$ a year at this hospital.

\section{Discussion}

Our system of managing home intravenous treatment for patients with cystic fibrosis has been safe, has proved successful in improving the patients' condition, and does not seem to be inferior to inpatient treatment.

Systems of managing outpatient intravenous antibiotic treatment have been advocated before ${ }^{8-10}$ but it is often undertaken on an informal ad hoc basis. Although there have been no reports of serious problems, there are inherent dangers with home intravenous treatment ${ }^{6}$ and a single serious accident may bring the whole practice into disrepute. Careful patient selection and training together with good venous access and observation when the first dose is given (that is, when the patient is at greatest risk of serious drug reaction) ${ }^{11}$ help to ensure safety. The time needed for training varies. It is wise to record in the notes that training has been completed and the person giving the drugs understands the dangers and is competent to give them. ${ }^{12}$ Our experience has convinced us that one of the most important contributions to safety and effectiveness is the provision of a member of the team who can regularly monitor progress, compliance, and stress in the home. Easy communications with members of the team are also vital, particularly if there are any signs of drug reactions or problems with intravenous access. These aspects of our system have allowed us to safely manage five incidents of drug reaction as well as pick up poor compliance, progress, and ability to cope. This has allowed us to make appropriate changes in management. The regular home visits and frequent communications with the family also have an important supportive role.

This study shows that home treatment is not without stress, but despite this most patients find it less stressful and prefer it to inpatient treatment.

Some parents may find home intravenous treatment unacceptably stressful and when this happens the child may see their parents' refusal to continue as an act of rejection. In this case it is important that the responsibility for a change to hospital treatment is taken by the caring team and not the parents.

We believe that home based intravenous treatment using the system we have described will become an attractive alternative to hospital treatment for many patients as more of them come under the care of units with large catchment areas and the staff and expertise to ensure effective implementation of such schemes. 
We thank the Cystic Fibrosis Research Trust for funding Dr J Gilbert, the Cystic Fibrosis Research Fellow, and the Joseph Levy Charitable Foundation for funding Sister Teresa Robinson, the Cystic Fibrosis Liaison Sister.

\section{References}

' Szaff M, Hoiby N, Flensborg EW. Frequent antibiotic therapy improves survival of cystic fibrosis patients with chronic Pseudomonas acruginosa infection. Acta Paediatr Scand 1983;72:651-7.

2 Meadow SR. The captive mother. Arch Dis Child 1969;44: $362-7$.

${ }^{3}$ Smith MA, Baum JD. Costs of visiting babies in special care baby units. Arch Dis Child 1983;58:56-9.

4 Pedersen SS, Koch C, Hoiby N, Rosendal K. An epidemic spread of multiresistant Pseudomonas acruginosa in a cystic fibrosis centre. J Antimicrob Chemother 1986;17:505-16.

5 Wang EEL, Prober CG, Manson B, Corey M, Levison $\mathbf{H}$. Association of respiratory viral infections with pulmonary deterioration in patients with cystic fibrosis. $N$ Engl $J$ Med 1984;311:1653-8.

- David TJ. Potential, practical and legal problems with home administration of intravenous antibiotics for children with cystic fibrosis. In: David TJ, ed. Cystic fibrosis in children. Practical and legal aspects of intravenous antibiotic administration in the home. Amsterdam: Excerpta Medica, 1986:3-14.

7 Bothe A, Piccione W, Ambrosino JJ, Benotti PN, Lokich JJ. Implantable central venous access system. Am J Surg 1984;147:565-9.

${ }^{8}$ Winter RJD, George RJD, Deacock SJ, Shee CD, Geddes DM. Self-administered home intravenous antibiotic therapy in bronchiectasis and adult cystic fibrosis. Lancet 1984;i:1338-9.

9 Bosso JA, Stephenson SEH, Herbst JJ. Feasibility and cost savings of intravenous administration of aminoglycosides in outpatients with cystic fibrosis. Drug Intell Clin Pharm 1985; 19:52-4.

${ }^{10}$ Kelly HW, Lovato C. Antibiotic use in cystic fibrosis. Drug Intell Clin Pharm 1984;18:772-81.

"Idsoe O, Guthe T, Willcox RR, De Weck AL. Nature and extent of penicillin side-reactions, with particular reference to fatalities from anaphylactic shock. Bull WHO 1968;38:159-88.

12 Murray WGD. The legal situation. In: David TJ, ed. Cystic fibrosis in children. Practical and legal aspects of intravenous antibiotic administration in the home. Amsterdam: Excerpta Medica, 1986:38-9.

Correspondence to Dr J Gilbert, Regional Cystic Fibrosis Unit, St Jame's University Hospital, Beckett Street, Leeds LS9 7TF.

Accepted 19 January 1988. 